CARDIAC PACING

\title{
Advances in Physiological Cardiac Stimulation
}

\author{
Gustavo Galli Reis ${ }^{1}$, Andrés Di Leoni Ferrari², Gustavo Chiari Cabrall,*, Guilherme Ferreira

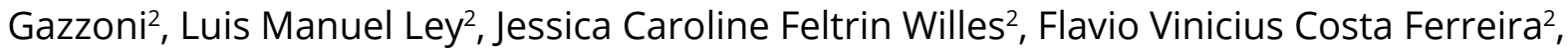 \\ Laura Orlandini Lodi²
}

\section{ORCID IDs}

Reis GG (D) https://orcid.org/0000-0002-8524-3401

Ferrari AL (D) https://orcid.org/0000-0001-8975-7912

Cabral GC (D) https://orcid.org/0000-0002-7992-8834

\author{
Gazzoni GF (D) https://orcid.org/0000-0001-5019-2475 \\ Ley LM (D) https://orcid.org/0000-0001-9640-6862 \\ Willes JCF (D) https://orcid.org/0000-0002-0891-4427 \\ Ferreira FVC (D) https://orcid.org/0000-0002-7186-707X \\ Lodi LO (D) https://orcid.org/0000-0003-1164-6483
}

\begin{abstract}
Advances in cardiac stimulation demonstrate that bradyarrhythmia treatments go beyond heart rate control. The concern with the ventricular stimulation site and, consequently, with the maintenance of intraventricular synchrony has become routine in most services. Techniques of physiological cardiac stimulation, such as stimulation of the bundle of His and the left branch, have been improved. Despite the indisputable benefits of these therapeutic modalities, there are technical difficulties that limit systematic use. In this sense, to make physiological cardiac stimulation more practical and reproducible, the concept of parahissian stimulation was expanded and studied. The technique, simpler and reproducible, contemplates a conventional approach of the right ventricle. The big difference is the use of QRS spatial variance analysis technology (Synchromax®, Exo S.A., Argentina) to confirm the maintenance of ventricular synchrony according to the implanted site.
\end{abstract}

KEYWORDS: Artificial cardiac stimulation; Atrioventricular fascicle; Artificial pacemaker; Disease of the cardiac conduction system; Cardiac insufficiency.

The practice of artificial cardiac pacing (ACP) has changed significantly in recent years. More and more experts are becoming aware that heart rate resolution is only part of the spectrum of bradyarrhythmia treatment.

Demonstratedly, conventional right ventricular (RV) ACP has a deleterious impact on cardiac hemodynamics due to electro mechanical changes in cardiac normal synchrony ${ }^{1}$.

Scientific evidence on the benefits of physiological cardiac stimulation, such as stimulation of the bundle of His and stimulation of the left branch, is increasingly robust and impacts even the reduction of mortality ${ }^{2}$.

1. Eletrofisiologia Cardíaca Londrina - Londrina (PR), Brazil.

2. Pontifícia Universidade Católica do Rio Grande do Sul - Hospital São Lucas - Porto Alegre (RS), Brazil.

*Autor correspondente: gu.cabral@uol.com.br

Recebido: 27 nov. 2020 | Aceito: 14 jan. 2021 
Despite the indisputable hemodynamic and clinical benefits of hissian or left bundle branch stimulation, some limitations hamper its standardization. Success rates vary significantly, on average from 60 to $90 \%$, there are technical difficulties, more time in the room and use of fluoroscopy, the need for mapping and additional tools, in addition to a higher rate of complications such as cardiac perforation, coronary injury, inadequate thresholds and thromboembolic events $\mathrm{s}^{3-5}$.

The basic principle of physiological ACP is the direct or indirect activation of the proximal portions of the native conduction system, thus making use of the extensive and specialized intrinsic electrical network of the heart.

In order to make the physiological ACP more practical and reproducible, the concept was expanded through parahissian stimulation. The technique consists of positioning the electrode in the most proximal region of the RV interventricular (IV) septum, adjacent to the conduction system. Thus, there is an indirect recruitment of the His-Purkinje system, similar to the non-selective stimulation of the His bundle.

ParaHissian pacing is performed with a conventional pacemaker lead, without the need for a sheath and with an exclusive approach to the right cardiac chambers. The procedure time and complication rates are similar to those of conventional ACP.

When electrically stimulating the Parahissian region, a QRS distinct from the native is obtained, as a result of the simultaneous capture of the conduction system and the adjacent septal musculature. The obtained QRS is, however, of short duration and preserves the axis of physiological activation (from top to bottom, from back to front and from right to left).

It should be noted that the simple fact that the electrode is anatomically positioned in the septum is not synonymous with IV synchrony or indirect His capture. To ensure ventricular synchrony, a QRS spatial variance analysis system Synchromax ${ }^{\circledR}$ (Exo S.A., Argentina) was developed.

Synchromax ${ }^{\circledR}$ is nothing more than a sophisticated non-invasive electrical surface mapping system in which, through the immediate synchrony index (imeSI), a graphical and mathematical processing of the signals originating from the variance of the DII leads (right IV septum) is performed and V6 (left ventricular lateral wall). For this, the software uses the measurement of the electric current flow (volume and direction) and the analysis of agreement of the intrinsicoid deflections of the $\mathrm{QRS}^{6}$.

ImeSI values range from 0 to 1 . When $<0.4$, they indicate IV synchrony; values between 0.41 and 0.69 reflect moderate dyssynchrony; and imeSI $>0.7$ indicate severe IV dyssynchrony. This analysis is done in real time, intraprocedure, allowing the specialist to optimize the final positioning of the electrode and thus guarantee Parahissian activation.

In a recent study, Ferrari et al. ${ }^{7}$ performed the IV synchrony analysis with the intraprocedure aid of this system. The study compared the IV synchrony obtained with parahissian stimulation (group DDD-Var) versus non-selective ACP of the bundle of His (group DDD-His). 51 patients were followed up, all with left ventricular ejection fraction (LVEF) greater than 35\% at the surgical occasion. The DDD-Var group was composed of 34 patients (66.7\%) and the DDD-His group of 17 patients (33.3\%). In the DDD-Var group, the analysis of the spatial variance of the QRS, using the ventricular synchrony index, showed an improvement in the post-implantation synchronization of a permanent pacemaker (pPM) ( $\mathrm{p}<0.001$ ). On post-implantation electrocardiogram, $91.2 \%$ of DDD-Var had a physiological pattern of ACP similar to that of DDD-His (88.2\% physiological pattern; $\mathrm{p}=0.999)$. For this physiological pattern analysis, the QRS electrical axis, the absence of RWPT ( $R$ wave peak time / intrinsicoid deflection) $\geq 100 \mathrm{~ms}$, the absence of Plateau in D1 and the absence of Notch in V1 were considered. Thus, it was possible to prove the indirect recruitment of His-Purkinje. Fluoroscopy time was significantly shorter for DDD-Var (median 7 vs. 21 minutes, $\mathrm{p}<0.001$ ). Despite the significant improvement in IV synchrony, the mean QRS duration in DDD-Var patients increased (114.7 pre-pPM vs. 128.2 ms post-implantation, $\mathrm{p}=0.044$ ). The amplitude of the $\mathrm{R}$ wave significantly favored the DDD-Var group (11.2 vs. $6.0 \mathrm{mV}$ DDD-His, $\mathrm{p}=0.001$ ).

This study demonstrated by specific electrocardiographic criteria that the parahissian ACP, guided by the intraprocedural analysis of the QRS spatial variance, approaches the non-selective capture of the His bundle in terms of cardiac synchrony. Perhaps, as proposed by these authors, these two types of stimulation will be referred to in the literature as indirect physiological ACP.

Parahissian stimulation guided by Synchromax represents a safe, economical and easily reproducible alternative, with good electromechanical results through the indirect recruitment of the bundle of His. It appears as an option to 
the traditional implant and to the hissian and left branch modalities. This technique contributes to the prevention of the harmful effects of IV dyssynchrony

The applicability of this non-invasive method of analyzing IV synchrony goes beyond the operating environment, and can be performed on an outpatient basis, to optimize multi vectorial programming of cardiac resynchronizers.

Further studies are needed to evaluate, in the medium and long term, the impact on clinical outcomes, such as the rate of hospitalization for decompensated heart failure, the incidence of atrial fibrillation, the maintenance of ventricular function and the mortality rate.

\section{REFERENCES}

1. Merchant FM, Mittal S. Pacing induced cardiomyopathy. J Cardiovasc Electrophysiol. 2020;31(1):286-92. https://doi.org/10.1111/ jce. 14277

2. Vijayaraman P, Naperkowski A, Subzposh FA, Abdelrahman M, Sharma PS, Oren JW, et al. Permanent His Bundle Pacing: Long-Term Lead Performance and Clinical Outcomes. Heart Rhythm. 2018;15(5):696-702. https://doi.org/10.1016/j.hrthm.2017.12.022

3. Vijayaraman P, Ellenbogen K. Approach to permanent His bundle pacing in challenging implants. Heart Rhythm. 2018;15(9):142831. https://doi.org/10.1016/j.hrthm.2018.03.006

4. Fischer AJ, Nagarajan VD, Yen Ho S, Diller G-P, Ernst S. Anatomic pitfalls and challenges of His bundle pacing. Herzschrittmacherther Elektrophysiol. 2020;31(2):104-10. https://doi.org/10.1007/s00399-020-00680-0

5. Ponnusamy SS, Arora V, Namboodiri N, Kumar V, Kapoor A, Vijayaraman P. Left Bundle Branch Pacing: A Comprehensive Review. J Cardiovasc Electrophysiol. 2020;31(9):2462-73. https://doi.org/10.1111/jce.14681

6. Bonominia MP, Ortega DF, Barjac LD, Manganic N, Arinia PD. Depolarization spatial variance as a cardiac dyssynchrony descriptor. Biomed Signal Process Control. 2019;49:540-5. https://doi.org/10.1016/j.bspc.2018.12.009

7. Ferrari AL, Gazzoni GF, Ley LM, Willes JCF, Cabral GC, Ferreira FV, et al. Análise da sincronia ventricular na estimulação cardíaca parahissiana como alternativa para ativação cardíaca fisiológica (estimulação indireta do feixe de His): resultados promissores? 2020. (no prelo.) 